\title{
Design for value change
}

\author{
Ibo van de Poel $^{1} \mathbb{D}$
}

Published online: 26 June 2018

(C) The Author(s) 2018, corrected publication 2021

\begin{abstract}
In the value sensitive design (VSD) literature, there has been little attention for how values may change during the adoption and use of a sociotechnical system, and what that implies for design. A value change taxonomy is proposed, as well as a number of technical features that allow dealing with value change.
\end{abstract}

Keywords Value sensitive design $\cdot$ Values $\cdot$ Value change $\cdot$ Robustness $\cdot$ Adaptability $\cdot$ Flexibility

Value sensitive design (VSD) aims at integrating values of ethical import from the start in the design process of new products and systems (Friedman et al. 2006). It is based on the assumption that we can distinguish the relevant values for design before technologies are actually used. It also seems to assume that these values remain stable during adoption and use. However, at least for some technologies these assumptions do not to hold. They are subject to what might be called 'value change', which may range from the emergence of new values in society, to changes in the relevance or priority of values for a specific technological design to changes in how values are exactly understood and specified for a technology. This brief contribution starts with a short discussion of what values are on basis of the VSD literature. Next, different types of value change are discussed and a value change taxonomy is proposed. The contribution ends with discussing three technical features of designed systems that might help to better deal with value change: adaptability, flexibility, and robustness.

\section{Values in VSD}

According to Friedman et al. (2006, p. 349), a value "refers to what a person or a group of people consider important in life." Although it seems true that most values refer to what

Ibo van de Poel

i.r.vandepoel@tudelft.nl

1 Section Ethics and Philosophy of Technology, Department of Values, Technology \& Innovation, Delft University of Technology, Jaffalaan 5, 2628 BX Delft, The Netherlands people consider important in life, it is less obvious that everything that people find important in life amounts to a value. It has been argued that values should be distinguished from mere preferences or interests of people. Van de Poel and Royakkers (2011, p. 72) therefore define values as "lasting convictions or matters that people feel should be strived for in general and not just for themselves to be able to lead a good life or realize a good society."

There has been debate in the VSD literature on whether values are universal or not (cf. Davis and Nathan 2015). Other authors have argued that VSD needs to be supplemented by an ethical theory to distinguish values that are morally worth striving for from values that are not (e.g. Manders-Huits 2011). In this respect, it has also been suggested that we should distinguish between instrumental values, i.e. values that are instrumental to achieving another good (or value) and intrinsic values, which are valuable for their own sake or are an end in themselves (e.g. Spiekermann 2015; Burmeister et al. 2011). ${ }^{1}$ There has also been debate whether VSD should start with a list of values, as can for example be found in Friedman et al. (2006), or should be more open-ended and should bottom-up elicit values from stakeholders (cf. Davis and Nathan 2015).

What seems to have been much less recognized in VSD is that values themselves may be subject to change during the lifetime of a product. Of course, if values are defined by lasting convictions about what is good or worth striving for, they will not change overnight. However, some designed products or systems have long lifetimes (Friedman and Nathan 2010) in which values may well change. An example are energy and transportation systems. At the ${ }_{1}$ Instrumental values have also been called extrinsic values and intrinsic values also sometimes have been called final values. 
time these systems were designed sustainability was not yet a central value, and we are now struggling to incorporate this value into these systems (Demski et al. 2015). However, also for products with shorter lifetimes, value change may occur. For example because it turns out that a product has unexpected side-effects, for instance on people's health or the environment. This may introduce new values that were not yet considered relevant or important during the design phase. An example are mobile phones that turn out to effect traffic safety. This value was not considered relevant before in mobile phone design, and still often is not incorporated. However, one might argue that given the evidence of how mobile phone use effects traffic safety (e.g. Violanti 1998), this value now has become relevant and should be taken into account in mobile phone design.

\section{Value change taxonomy}

Value change can occur in a variety of ways. One distinction is with respect to where value change originates. VSD takes an interactional stance with respect to the embedding of values: values result from the interaction of users and other stakeholders with technology (Friedman et al. 2006, p. 361). In line with this stance, we may distinguish between value changes that primarily occur due to social developments and value changes that are induced by technology. An example of a technology that has changed our values are contraceptives which have had an effect on sexual morality (Swierstra 2013). Another example are social media, like Facebook. Studies suggest that the use of Facebook has led to more lax attitudes towards privacy even if people have good reasons to be concerned about privacy intrusions (Debatin et al. 2009).

In addition to distinguishing sources of value change, we may also distinguish different degrees of value change. A first thing to note here is that the verdict of whether a value has changed, and to what degree it has changed, depends on how that value is exactly defined. It is particularly important at what level of abstraction, or generality, a value is characterized. Usually values are characterized at a rather abstract or general level; they are typically referred to with one abstract noun, like safety, sustainability, privacy or wellbeing, although also longer expressions occur.

One of the consequences of the fact that values are often understood at a high level of conceptual abstraction, is that changes in the understanding or interpretation of a value can occur while the value itself remains the same. Thus, safety may be understood as the absence of risk, or as the reduction of risks in as far as reasonably possible and desirable, but both understandings refer to the same value, i.e. 'safety'. In car design, safety may refer to the safety of the driver and passengers (occupant safety) or to the safety of bystanders like pedestrians and cyclists (pedestrian safety), and while in car design the emphasis was originally mainly on the first it has gradually also become to involve the second (Simms and Wood 2009). This can be interpreted as a change in how the value of safety is conceptualized and specified, but it could also be interpreted, if values are understood at a somewhat lower level of abstraction, as a change in the relative importance of the values of occupant safety and pedestrian safety. So how we exactly characterize value change is at least partly dependent on the level of abstraction that we use to characterize values.

With this in mind, it is nevertheless possible to distinguish between different kinds of value change:

1. The emergence of new values;

2. Changes in what values are relevant for the design of a certain technology;

3. Changes in the priority or relative importance of values;

4. Changes in how values are conceptualized;

5. Changes in how values are specified, and translated into norms and design requirements.

\section{Emergence of new values}

Although it may be hard to pinpoint when, and how quickly, new values exactly emerge, at least in retrospect, it is often possible to distinguish new values that have emerged over time. One example is the value of sustainability. The value has particular gained prominence since the Brundlandt Report on sustainable development that appeared in 1987 (WCED 1987), although it can be argued that the value itself is older. Nevertheless it is striking that in the list of intrinsic values based on the philosophical literature that is given by Frankena (1973, p. 72), it is not mentioned, and even values like environmental care, or nature or ecology are not mentioned as intrinsic values in his list. This might be explained by the fact that sustainability as a value has become important due to the increased impact of mankind on the environment in the last decades or century, which is in turn partly due to technological developments.

\section{Changes in what values are relevant for the design of a certain technology}

Apart from cases where new values emerge, there may also be cases in which values become relevant for the design of a technology where they were previously not. Here it is important to keep in mind that what values are relevant for a technology depends on what evaluative dimensions, such as safety, sustainability or privacy, a technology does, or can potentially impact. So one reason, as already briefly alluded to above, for values becoming relevant for the design of a technology is that technology turns out to impact certain 
evaluative dimensions that were not considered relevant before. The example that was earlier given is mobile phones that turned out to effect traffic safety, which makes this a new evaluative dimension and a new value that should be taken into account in mobile phone design. Changes in the relevance of values may also result from broader social changes. For example, another concern that has come up in relation to mobile phone design is that the use of some rare materials in phones like tantalum contribute to the financing of civil conflicts in for example Congo. Some phone manufactures, like Fairphone, in response have developed phones with 'conflict-free' or fair materials (Fairphone 2017). Fairness is thus a value that has become relevant in phone design for some companies, not only with respect to tantalum but also with respect to other rare materials.

\section{Changes in the priority or relative importance of values}

A third type of value change is a change in the relative importance of values. Typically, design needs to take into account a range of values, and design choices that prioritize some values over others may sometimes be inevitable. The judgement on which values to prioritize or how to balance or weigh values may change in the course of time. An example that was already mentioned above is car design. Here the relative importance of the values of occupant and pedestrian safety has developed over time, with pedestrian safety becoming increasingly important. This category is different from the previous one because pedestrian safety was already concerned a relevant value; only its relative importance has increased.

\section{Changes in how values are conceptualized}

Also the conceptualization of a value may change. Conceptualization is here understood as "the providing of a definition, analysis or description of a value that clarifies its meaning" (Van de Poel 2013, p. 261). Privacy nowadays is often understood as informational privacy. Privacy, however, also has other, including bodily, connotations that might be important in the design of certain devices (like for example Google Glass). Koops et al. (2017) have proposed a typology of privacy that distinguishes eight types of privacy (bodily, intellectual, spatial, decisional, communicational, associational, proprietary, and behavioral) and they conceive of informational privacy as a concept that overlaps but does not coincide with these eight basic types.

\section{Changes in how values are specified}

One way in which values can be effectuated in design is by translating them into norms and design requirements (Van de Poel 2013). This process can be called specification. It is to be distinguished from the previous level that is about how a value is understood or conceptualized at a general level. In contrast, specification is about how a value is understood in a specific case and specification is typically more contextdependent than conceptualization: how a value is specified depends on the kind of technology that is designed. Specifications may, however, change over time. An example given in Van de Poel (2013) is the specification of the value of animal welfare in chicken husbandry systems. Whereas in earlier specifications (in the law), battery cages were seen as systems that could meet the value of animal welfare, in later specifications these systems were seen as unacceptable.

\section{Some technical features of designed systems that allow for better dealing with value change}

Three technical features of designed products or systems are discussed that allow to better deal with value change: adaptability, flexibility, and robustness. These features can be designed into products or systems so that they can better adapt to changing values in the later phases of the life cycle of a product or system.

\section{Adaptability}

Adaptability of a design can be understood in different ways. Here it will be understood as the possibility to change the composition or configuration of an artifact or system in order to better perform the original function (or to perform the function in new circumstances), or to perform a new function. In terms of values, this may be supplemented by changes in the composition or configuration to better respect the relevant values or to respect new values.

Adaptability is different from robustness (which is discussed below) in two important ways. First, it is not only aimed at performing the given function or meeting a set or predefined values, but also allows performing new functions or meeting new values. This means that it can also deal with the higher levels of value change in the value change taxonomy. Second, it requires an intervention of an actor to change the composition or configuration of the artifact or system. This can be the designers, but also users or operators (of the system).

One way in which adaptability can be achieved or improved is by modularization of the design, so that the design exits of different modules that can be replaced or can be reconfigured. In terms of function performance, it may be possible to modularize the design in such a way that different modules also fulfill different sub-functions. It is less clear whether such strategies can also be helpful for VSD. 
It would seem that in many cases, guaranteeing the safety, privacy or sustainability of a system is not a matter of adding certain modules to the design but rather is to be understood as the system level, i.e. as the result of the interaction between different modules rather than as something that can be guaranteed by the presence of one specific module.

\section{Flexibility}

Like adaptability, flexibility can be understood in different ways, some of which are quite similar to adaptability. To distinguish the two concepts, adaptability is here understood in terms of the possibility to change the composition or configuration of the design, while flexibility is understood in terms of different possibilities for using the design. Use is understood here broadly as any action with the designed artifact or system that does not change its initial design.

Most designed products and systems are somewhat flexible in use. Sometimes this flexibility is intended by the designers; at other occasions designers try to limit the flexibility of a design. A reason why designers sometimes want to limit flexibility is that flexibility might decrease the likeliness that a design performs its function or, in case of VSD, that a design respects a range of relevant values. At the same time, flexibility may allow other kinds of use that make it possible for the artefact to perform its function in new circumstances or to perform different functions. Similarly, flexibility may allow for better meeting certain values in new circumstances, or may allow dealing with value change.

Flexibility then is really a double-edged sword. If we could perfectly predict the world and if the designers (after consulting or involving the stakeholders) exactly know what functions a design is to perform and what values it is to meet, flexibility would not seem necessary or even undesirable. It would be undesirable because lack of flexibility would avoid misuse or the possibility that an artefact is used, for example, unsafely or unsustainably. However, in a world that is only to a limited degree predictable and in which value change occurs, flexibility would seem in many cases desirable.

\section{Robustness}

Robustness in design is often understood as the ability of a design to perform its function despite variety in the product, use and external circumstances (e.g. Taguchi et al. 2000). It is thus related to the ability to perform in new or somewhat unexpected circumstances. For VSD designs, robustness might be understood as the ability of a design to respect certain values despite variety, including use in new circumstances. In the light of the possibility of value change, we may add to this that the values should also be met if these values are specified or conceptualized somewhat differently or if the priority of values changes. We may then define what we can call value robustness as 'the ability of a design to perform its function while respecting a range of values despite variety in, among others, circumstances in which the design has to function and variety in how the relevant values are exactly specified, conceptualized or prioritized.' It should be noted that, so defined, value robustness may help to deal with the types of value change at level 3 through 5 from the value change taxonomy, but not at the highest two levels. These levels may require adaptability (for value change) or (value) flexibility.

\section{Conclusion}

VSD should not only proactively address values during the design process, but should also take into account the possibility of value change. Such value change can occur to different degrees, from the emergence of new values to respecification of current values in design. Three technical features have been discussed that can designed into products and systems so that they are better able to deal with value change: adaptability, flexibility, and robustness.

Acknowledgements This paper was written for the Lorentz Workshop "Value Sensitive Design: Charting the Next Decade" that was held in November 2016. I would like to thank the organizers for the opportunity to write the paper and the editor of the special issue and two anonymous referees for their useful comments. The completion of this articles was part of the project Valued Change that has received funding from the European Research Council (ERC) under the European Union's Horizon 2020 research and innovation programme under grant agreement No 788321 .

Open Access This article is distributed under the terms of the Creative Commons Attribution 4.0 International License (http://creativeco mmons.org/licenses/by/4.0/), which permits unrestricted use, distribution, and reproduction in any medium, provided you give appropriate credit to the original author(s) and the source, provide a link to the Creative Commons license, and indicate if changes were made.

\section{References}

Burmeister, O. K., Weckert, J., \& Williamson, K. (2011). Seniors extend understanding of what constitutes universal values. Journal of Information, Communication and Ethics in Society, 9(4), 238-252. https://doi.org/10.1108/14779961111191048.

Davis, J., \& Nathan, L. P. (2015). Value sensitive design: Applications, adaptations and critiques. In J. van den Hoven, P. E. Vermaas, \& I. Van de Poel (Eds.), Handbook of ethics and values in technological design (pp. 11-40). Dordrecht: Springer.

Debatin, B., Lovejoy, J. P., Horn, A.-K., \& Hughes, B. N. (2009). Facebook and online privacy: Attitudes, behaviors, and unintended consequences. Journal of Computer-Mediated Communication, 15(1), 83-108. https://doi.org/10.1111/j.1083-6101.2009.01494.x. 
Demski, C., Butler, C., Parkhill, K. A., Spence, A., \& Pidgeon, N. F. (2015). Public values for energy system change. Global Environmental Change, 34, 59-69. https://doi.org/10.1016/j.gloenvcha. 2015.06.014.

Fairphone (2017). https://shop.fairphone.com/en/. Accessed 28 June 2017.

Frankena, W. K. (1973). Ethics (2nd ed.). Englewood Cliffs: Prentice Hall.

Friedman, B., Kahn, P. H. J., \& Borning, A. (2006). Value sensitive design and information systems. In P. Zhang \& D. Galletta (Eds.), Human-computer interaction in management information systems: Foundations (Vol (5, pp. 348-372). Advances in Management Information Systems). Armonk: M E Sharpe.

Friedman, B., \& Nathan, L. P. (2010). Multi-lifespan information system design: A research initiative for the hci community. Paper presented at the Proceedings of the SIGCHI Conference on Human Factors in Computing Systems, Atlanta, Georgia, USA.

Koops, B.-J., Newell, B. C., Timan, T., Ivan Škorvánek, T., Chokrevski, \& Galič, M. (2017). A typology of privacy. University of Pennsylvania Journal of International Law, 38(2), 483-575.

Manders-Huits, N. (2011). What values in design? The challenge of incorporating moral values into design. Science and Engineering Ethics, 17(2), 271-287. https://doi.org/10.1007/ s11948-010-9198-2.
Simms, C., \& Wood, D. (2009). Vehicle design standards for pedestrian and cyclist safety. In C. Simms \& D. Wood (Eds.), Pedestrian and cyclist impact: A biomechanical perspective (pp. 99-114). Dordrecht: Springer Netherlands.

Spiekermann, S. (2015). Ethical IT innovation: A value-based system design approach. Boca Raton: CRC Press.

Swierstra, T. (2013). Nanotechnology and technomoral change. Etica \& Politica/Ethics \& Politics, XV(1), 200-219.

Taguchi, G., Chowdhury, S., \& Taguchi, S. (2000). Robust engineering. New York: McGraw-Hill.

Van de Poel, I. (2013). Translating values into design requirements. In D. Mitchfelder, N. McCarty \& D. E. Goldberg (Eds.), Philosophy and engineering: Reflections on practice, principles and process (pp. 253-266). Dordrecht: Springer.

Van de Poel, I., \& Royakkers, L. (2011). Ethics, technology and engineering. Oxford: Wiley-Blackwell.

Violanti, J. M. (1998). Cellular phones and fatal traffic collisions. Accident Analysis \& Prevention, 30(4), 519-524. https://doi.org/10. 1016/S0001-4575(97)00094-8.

WCED. (1987). Our common future. Report of the world commission on environment and development. Oxford: Oxford University Press. 